\title{
Spread of a multiresistant CTX-M-9-producing Salmonella enterica serotype Virchow phage type 19 in Spain
}

\author{
S. Herrera-León • R. González-Sanz • I. Rodríguez • \\ M. R. Rodicio • M. A. Echeita
}

Received: 17 November 2009/Accepted: 3 April 2010 / Published online: 6 May 2010

(C) Springer-Verlag 2010

\begin{abstract}
The purpose of this study was to survey Salmonella enterica serotype Virchow phage type 19 (S. Virchow PT19) strains submitted to the Spanish National Reference Laboratory for Salmonella (SNRLS) from 2002 to 2006 in order to determine the rate type and genetic background of $\beta$-lactam resistance and to further identify the associated resistances. Ninety-nine $S$. Virchow PT19 strains were analysed. Antimicrobial susceptibility was determined by the disk diffusion method using Mueller-Hinton agar medium. Polymerase chain reaction (PCR) assays and, later, sequencing of the obtained fragments were performed for the molecular characterisation of the resistances. Pulsed-field gel electrophoresis (PFGE) and plasmid analysis (using conjugation, Southern blot hybridisation and replicon typing) were used for characterisation. The characterisation of $S$. Virchow PT19 strains allowed the identification of a clonal multiresistant $S$. Virchow PT19 harbouring an IncH12 plasmid with the $b l a_{\text {CTX-M-9 }}$ gene within the complex integron In60
\end{abstract}

S. Herrera-León · R. González-Sanz • M. A. Echeita

Servicio de Bacteriología, Centro Nacional de Microbiología, Instituto de Salud Carlos III,

Ctra. Majadahonda-Pozuelo km2,

28220 Majadahonda, Madrid, Spain

I. Rodríguez $\cdot$ M. R. Rodicio

Departamento de Biología Funcional, Área de Microbiología,

Universidad de Oviedo,

C/ Julian Clavería s/n,

33006 Oviedo, Spain

S. Herrera-León $(\varangle)$

Sección de Enterobacterias, Centro Nacional de Microbiología, Instituto de Salud Carlos III,

Ctra. Majadahonda-Pozuelo km2,

28220 Majadahonda, Madrid, Spain

e-mail: sherrera@isciii.es distributed across Spain. An IncH12 plasmid widely reported and studied in Enterobacteria is described in a clonal multiresistant $S$. Virchow PT19 which has successfully spread throughout Spain

\section{Introduction}

Antimicrobials, specifically extended-spectrum-cephalosporins and fluoroquinolones, are often essential for the treatment of invasive infections caused by Salmonella spp. However, it is well known that these organisms have been successful at acquiring resistance to a broad range of commonly used antimicrobials, including those previously described [1]. The prevalence of multidrug-resistant (MDR) phenotypes has increased in developed countries mostly due to the mobility of antimicrobial-drug-resistant determinants, mediated by genetic elements such as integrons, transposons and plasmids [2]. An important factor associated with this increase among particular Salmonella serotypes is the national and international spread of certain clonal genotypes, such as the global epidemic spread of MDR $S$. Typhimurium DT104 or the spread in the USA of the MDR strain of ceftriaxone-resistant $S$. Newport. Salmonella spp. accounts for more than 2,500 serotypes. About 2000 are capable of infecting humans, but only a few have assumed great significance. $S$. Virchow ranks third in many European countries, although it accounts for $<4 \%$ of all non-typhoidal Salmonella serotypes [3]. A $S$. Virchow phage type 19 (PT19) strain producing a CTX-M-9 $\beta$ lactamase was detected in our laboratory in 2002. In order to assess the current presence and spread of this organism and to determine its resistance properties, the present work screened a large collection of $S$. Virchow strains isolated from 2002 to 2006 in Spain. 


\section{Materials and methods}

Strains and phage typing

The Spanish National Reference Laboratory for Salmonella (SNRLS) received $504 \mathrm{~S}$. Virchow out of 39,045 Salmonella strains isolated from 2002 to 2006. Phage typing was performed according to Chambers et al. [4], with phages and interpreting criteria provided by the Health Protection Agency (HPA, formerly Public Health Laboratory Service, Colindale) in London, England. Only S. Virchow PT19 isolates with no epidemiological link among them were selected for further studies.

\section{Antimicrobial testing}

The S. Virchow PT19 isolates were checked for susceptibility by the disk diffusion method on Mueller-Hinton agar to the following antimicrobial drugs: ampicillin (Amp, $10 \mu \mathrm{g}$ ), cephotaxime (Ctx, $30 \mu \mathrm{g}$ ), amoxicillin/ clavulanic acid (AMC, $30 \mu \mathrm{g})$, streptomycin (, $10 \mu \mathrm{g})$, kanamycin (K, $30 \mu \mathrm{g})$, gentamicin (Gen, $10 \mu \mathrm{g})$, chloramphenicol $(\mathrm{Cm}, 30 \mu \mathrm{g})$, tetracycline $(\mathrm{T}, 30 \mu \mathrm{g})$, nalidixic acid ( $\mathrm{Na}, 30 \mu \mathrm{g}$ ), ciprofloxacin (Cip, $5 \mu \mathrm{g}$ ), sulphonamides $(\mathrm{Su}, 300 \mu \mathrm{g})$ and trimethoprim/sulphamethoxazole (SxT, $25 \mu \mathrm{g})$. The breakpoints used were those defined by the Clinical Laboratory Standards Institute (CLSI) for Enterobacteriaceae [5]. Extended-spectrum $\beta$ lactamase (ESBL) phenotype was detected by the double disk synergy test (DDST).

\section{$\beta$-lactamases detection}

Crude extracts from the 79 isolates with a positive DDST were obtained by sonication followed by centrifugation, and isolectric focusing was performed with a PhastSystem apparatus (GE HealthCare, Barcelona, Spain) using PhastGel IEF gels with gradient 3-9. Confirmation of the presence and type of an ESBL gene was done by polymerase chain reaction (PCR) and sequencing [6].

Pulsed-field gel electrophoresis

Clonality among ESBL-producing isolates was assessed by pulsed-field gel electrophoresis (PFGE) following the standard protocol of PulseNet Europe (http://www.pulseneteurope.org/docs.htm). Fingerprints were compared with InfoQuest v.4.5 (BioRad Laboratories, Hercules, CA, USA). Pattern clustering was performed by using the unweighted pair group method with an arithmetic mean and the Dice coefficient with a tolerance of $0.5 \%$. Fragments smaller than $30 \mathrm{~kb}$ were disregarded according to PulseNet guidelines for standardisation. Isolates with electrophoretic patterns that differed by one band were assigned to different PFGE types.

Detection of resistance determinants

Nineteen strains (V1 to V19) were selected for further characterisation based on differences on antimicrobial resistance profiles and/or different pulse types. Detection and characterisation of class 1 integrons, gene cassettes within the variable regions, specific sequences for In60, additional resistance genes compatible with the different phenotypes and study of the quinolone resistance-determining region of gyr $A$ of nalidixic acidresistant isolates were performed as described previously [6-8].

Conjugation assays and plasmid analysis

Conjugation assays were performed with a rifampicinresistant recipient, Escherichia coli K12 J53, using in-broth methods [6]. PFGE with S1 nuclease digestion of whole genomic DNA was used to detect large plasmids in $S$. Virchow strains and their transconjugants [6]. Both XbaI and S1 fragments from $S$. Virchow and their transconjugants were transferred onto nylon membranes and hybridised with PCR-generated probes of $863 \mathrm{bp}$ and 1,597 bp, specific for the bla $a_{\mathrm{CTX}-\mathrm{M}-9}$ gene and the variable region of a complex class 1 integron detected in the present study, respectively [6]. PCR-based replicon typing was performed as described by Carattoli et al. [9] using DNA from the transconjugants as the template.

\section{Results and discussion}

Of a total of $504 \mathrm{~S}$. Virchow strains received by the SNRLS during 2002 to 2006, 99 strains isolated from sporadic cases $(19.64 \%)$ were PT19. They were submitted from 14 out of the 17 Spanish provinces. All 99 strains were susceptible to amoxicillin/clavulanic acid and ciprofloxacin. A total of $90.2 \%$ isolates were resistant to ampicillin, $85.9 \%$ to cefotaxime, $62 \%$ to kanamycin, $84.8 \%$ to streptomycin, $2.2 \%$ to gentamycin, $91.3 \%$ to nalidixic acid, $73.9 \%$ to tetracycline, $3.3 \%$ to cloramphenicol, $87 \%$ to sulphonamides and $87 \%$ to cotrimoxazole. Seventy-nine out of $99 \mathrm{~S}$. Virchow PT19 isolates showed antimicrobial susceptibility patterns compatible with ESBL production. Multiple drug resistance (resistance to $\geq 3$ groups of drugs) was observed in all ESBL-producing isolates except one. The different antimicrobial resistance phenotypes were: AmpCtxKSTSuSxTNa (42 strains), AmpCtxSTSuSxTNa (16 strains), AmpCtxKSSuSxTNa (9 strains), AmpCtxSSuSxTNa (6 strains), AmpCtxKTSuSxTNa (4 strains), 
AmpCtxSTSuSxT (1 strain) and AmpCtxNa (1 strain). Eleven different pulse types (P1 to P11) were observed among the 79 ESBL-producing strains. The genetic similarity was $89 \%$. All isolates except one (V19, Table 1) were highly related (similarity $\geq 91 \%$ ), which may indicate clonal spread of those resistances. Forty-nine strains $(62 \%)$ belonged to P1. The most common antimicrobial profile within this pulse type, widely distributed over Spain, was AmpCtxKSTSuSxTNa (Table 1). Isoelectric focusing showed that all isolates produced two $\beta$-lactamases with isoelectric points of 5.4 and 7.9 except one (V1, Table 1), which only produced the second one. PCR and sequencing techniques confirmed that these values corresponded to
TEM-1 and CTX-M-9 $\beta$-lactamases, respectively. Nineteen strains (V1 to V19) were selected for further characterisation based on differences on antimicrobial resistance profiles and/or different pulse types. The resistance genotypes of those strains are shown in Table 1. Apart from V16, all isolates contained a class 1 integron with the variable region (dfrA16-aadA2) and three other regions (orf513, orf3-like and orf1005) characteristic of In60, where the $b l a_{\text {СтХ-M-9 }}$ is located [7]. The sequences of the variable regions and of orf 513 were $100 \%$ and $99 \%$ identical to the corresponding sequences of In36 and In60, respectively, while the sequences of orf3-like and orf1005 (not present in the In36 integron) were 100\%

Table 1 Molecular properties of $S$. Virchow PT19 strains selected for further characterisation of the resistances

\begin{tabular}{|c|c|c|c|c|c|}
\hline Strain & Pulse type & Class 1 integron & R-phenotype/R-genotype & Plasmid size (kb) & Tc plasmid size $(\mathrm{kb})$ \\
\hline $\mathrm{V} 1$ & 1 & $1600_{d f r 16, \text { aad } \mathrm{A} 2}$ & $\begin{array}{l}\text { Amp Ctx K S T Su SxT Na } \\
\text { bla }_{\mathrm{CTX}-\mathrm{M}-9} \text { aphA1 aadA2 str } \mathrm{AB} \\
\text { tetA sul1 } d f r 16 \text { Ser83Phe }\end{array}$ & NO & 330 \\
\hline $\mathrm{V} 2$ & 1 & $1600_{d f r 16, \text { aadA2 }}$ & $\begin{array}{l}\text { Amp Ctx S T Su SxT Na } \\
\text { bla } \text { TEM-1, CTX-M-9 aadA2 tetA } \\
\text { sul } 1 \text { dfr } 16 \text { Ser83Phe }\end{array}$ & 325 & 325 \\
\hline V3 & 1 & $1600_{d f r 16, \operatorname{aad} \mathrm{A} 2}$ & $\begin{array}{l}\text { Amp Ctx K S T Su SxT Na } \\
\text { bla TEM-1, CTX-M-9 aphA1 aadA2 tetA } \\
\text { sul1 } d \text { fr } 16 \text { Ser83Phe }\end{array}$ & 260 & 260 \\
\hline V4 & 1 & $1600_{d f r 16, \operatorname{aad} \mathrm{A} 2}$ & $\begin{array}{l}\text { Amp Ctx K S Su SxT Na } \\
\text { bla } \text { TEM-1, CTX-M-9 aphA1 aadA2 str AB } \\
\text { sul } d \text { fr } 16 \text { Ser83Phe }\end{array}$ & 340 & 340 \\
\hline V5 & 1 & $1600_{d f r 16, \text { aad } \mathrm{A} 2}$ & $\begin{array}{l}\text { Amp Ctx K S T Su SxT Na } \\
\text { bla } \text { TEM-1, CTX-M-9 aphA1 aadA2 strAB } \\
\text { tetA sul } 1 \text { dfr } 16 \text { Ser83Phe }\end{array}$ & 340 & $\mathrm{NC}$ \\
\hline V6 & 1 & $1600_{d f r 16, \text { aad } \mathrm{A} 2}$ & $\begin{array}{l}\text { Amp Ctx K S Su SxT Na } \\
\text { bla } \text { TEM-1, CTX-M-9 aphA1 aadA2 str AB } \\
\text { sul1 } d \text { fr } 16 \text { Ser83Tyr }\end{array}$ & 330 & 330 \\
\hline V7 & 2 & $1600_{d f r 16, \operatorname{aadA} 2}$ & $\begin{array}{l}\text { Amp Ctx K S T Su SxT Na } \\
\text { bla } \text { TEM-1, CTX-M-9 aphA1 aadA2 str } \mathrm{AB} \\
\text { tet } \mathrm{A} \text { sul } 1 \text { dfr } 16 \text { Ser83Phe }\end{array}$ & $\mathrm{NO}$ & 275 \\
\hline V8 & 3 & $1600_{d f r 16, \text { aad } \mathrm{A} 2}$ & $\begin{array}{l}\text { Amp Ctx K S T Su SxT Na bla } \text { тем-1, Стх-м-9 } \\
\text { aphA1 aadA2 strAB tetA } \\
\text { sul } 1 \text { dfr } 16 \text { Ser83Phe }\end{array}$ & 320 & 320 \\
\hline V9 & 3 & $1600_{d f r 16, \text { aad } 22}$ & $\begin{array}{l}\text { Amp Ctx S Su SxT Na bla TЕм-1, СтХ-м-9 } \\
\text { aadA2 tetA sul1 dfr16 Ser83Phe }\end{array}$ & 290 & $\mathrm{NC}$ \\
\hline V10 & 4 & $1600_{d f r 16, \text { aad } \mathrm{A} 2}$ & $\begin{array}{l}\text { Amp Ctx K S T Su SxT Na bla } \\
\text { aphA1 aadA2 strAB tetA sull } d f r 16 \text { Ser83-M-9 } \\
\text { Sere }\end{array}$ & NO & 330 \\
\hline V11 & 4 & $1600_{d f r 16,} \operatorname{aad\mathrm {A}2}$ & $\begin{array}{l}\text { Amp Ctx K S Su SxT Na bla TEM-1, СтX-M-9 } \\
\text { aphA1 aadA2 strAB sul } d f r 16 \text { Ser83Phe }\end{array}$ & 290 & 290 \\
\hline V12 & 5 & $1600_{d f r 16, \text { aad } 22}$ & $\begin{array}{l}\text { Amp Ctx K S T Su SxT Na bla } \\
\text { aphA1 aadA2 strAB tetA sul1 } d f r 16 \text { Ser83Phe }\end{array}$ & 290 & $\mathrm{NC}$ \\
\hline V13 & 6 & $1600_{d f r 16, \text { aad } \mathrm{A} 2}$ & $\begin{array}{l}\text { Amp Ctx K S T Su SxT Na bla } \\
\text { aphA1 aadA2 strAB tetA sul1 } d f r 16 \text { Ser83Phe }\end{array}$ & 360 & 360 \\
\hline V14 & 7 & $1600_{d f r 16, \text { aad } \mathrm{A} 2}$ & $\begin{array}{l}\text { Amp Ctx K S Su SxT Na bla TEM-1, CTX-M-9 } \\
\text { aphA1 aadA2 strAB sul1 } d f r 16 \text { Ser83Phe }\end{array}$ & 290 & 290 \\
\hline V15 & 7 & $1600_{d f r 16, \text { aad } \mathrm{A} 2}$ & $\begin{array}{l}\text { Amp Ctx S T Su SxT Na bla TEM-1, СтX-M-9 } \\
\text { aadA2 tetA sul1 dfr16 Ser83Phe }\end{array}$ & 300 & 300 \\
\hline V16 & 8 & $-^{*}$ & Amp Ctx S Su bla TEM-1, СТХ-М-9 strAB sul1 & 340 & 340 \\
\hline V17 & 9 & $1600_{d f r 16, \text { aad } \mathrm{A} 2}$ & $\begin{array}{l}\text { Amp Ctx K S T Su SxT Na bla Tем-1, СтХ-м-9 } \\
\text { aphA1 aadA2 strAB tetA } \\
\text { sul } 1 \text { dfr } 16 \text { Ser83Phe }\end{array}$ & 340 & 340 \\
\hline
\end{tabular}


Table 1 (continued)

\begin{tabular}{llllll}
\hline Strain & Pulse type & Class 1 integron & R-phenotype/R-genotype & Plasmid size (kb) & Tc plasmid size (kb) \\
\hline V18 & 10 & $1600_{d f r 16, \text { aadA2 }}$ & $\begin{array}{c}\text { Amp Ctx K S T Su SxT Na bla TEM-1, CTX-M-9 } \\
\text { aphA1 aadA2 strAB tetA sul1 dfr16 Ser83Phe }\end{array}$ & $241+50$ & 315 \\
V19 & 11 & $1600_{d f r 16, \text { adA2 } 2}$ & $\begin{array}{c}\text { Amp Ctx K S T Su SxT Na bla } \text { TEM-1, CTX-M-9 } \\
\text { aphA1 adA2 tetA sul1 dfr16 Ser83Phe }\end{array}$ & 215 & NC
\end{tabular}

*: negative results; NO: not obtained; NC: not conjugative

Amp: ampicillin; Ctx: cefotaxime; K: kanamycin; S: streptomycin; T:tetracycline; Su: sulphonamides compound; SxT: trimethoprim sulphamethoxazole; Na: nalidixic acid

identical to the equivalent regions of In60 (GenBank accession number AF174129).

In all parental strains except three (V1, V7 and V10; Table 1), plasmid DNA molecules, ranging in size from 50 to $360 \mathrm{~kb}$, were visualised by S1 PFGE. E. coli transconjugants were obtained for all of the isolates tested except four (V5, V9, V12 and V19; Table 1). The transconjugants exhibited the same antimicrobial profile as their parental $S$. Virchow strains, except for resistance to nalidixic acid. Transconjugants harboured the same plasmids as their donor strains, with the exceptions of V1, V7, V10 and V18. Furthermore, in V1, V7 and V10, three plasmids (330, 275 and $330 \mathrm{~kb}$, respectively) could only be detected after conjugation. The donor strain V18 presented two plasmids. One of them, of size $240 \mathrm{~kb}$, hybridised with the $b l a_{\text {СтХ-М-9 }}$ and class 1 integron probes, whereas the other, of size $50 \mathrm{~kb}$, did not hybridise with any probe. Nevertheless, the transconjugant presented a single plasmid of about $300 \mathrm{~kb}$ that hybridised with both probes. This size is consistent with a fusion of the two plasmids found in the donor strain. Probes for the variable region of the class 1 integron and for bla $a_{\mathrm{CTX}-\mathrm{M}-9}$ mapped on large extrachromosomal fragments detected by S1 PFGE in the strains and/or their transconjugants, with the single exception of isolate V16, which was negative for the class 1 integron (Fig. 1, panel B; Table 1). Similarly, both probes mapped together on XbaI fragments of all parental strains except for V16 that failed to hybridise with the integron probe (Fig. 1). Differences in sizes between XbaI and S1 hybridising fragments could be explained by the presence of two or more XbaI restriction sites within the plasmids.

$S$. enterica isolates harbouring ESBLs have emerged worldwide as being the CTX-M type which is of particular importance. Although the number of isolations of $S$. Virchow is low compared to those of $S$. Enteritidis or $S$. Typhimurium, the increase in resistance to several key antimicrobials is concerning. Since $S$. Virchow is a serotype with a predilection for extra-intestinal spread, such resistance could have therapeutic implications. S. Virchow CTX-M-9producer has been already reported from both human and poultry origin in Spain and France, suggesting a relationship among animal and human $b l a_{\mathrm{CTX}-\mathrm{M}-9 \text {-containing isolates }}$

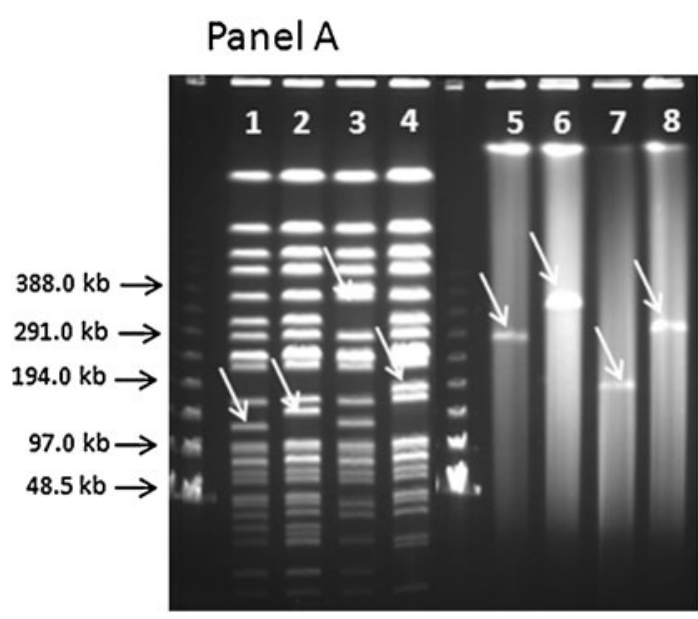

Panel B

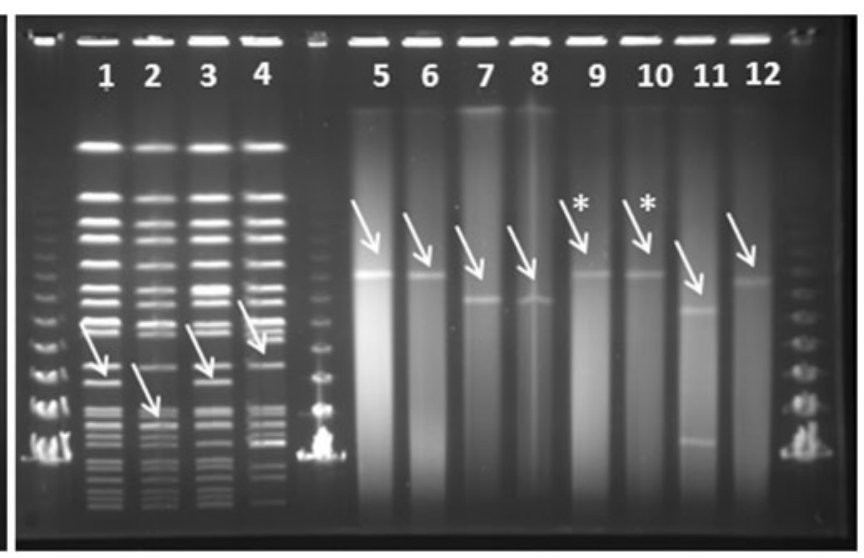

Panel C

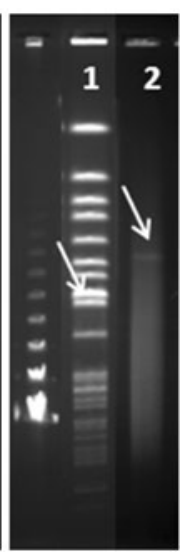

Fig. 1 Examples of the mapping of CTX-M-9 and class 1 integron on XbaI and S1 PFGE profiles of $S$. Virchow PT19 and their transconjugants. Fragments that hybridised with probes are marked with white arrows. Panel A. Isolates negatives for conjugations. Lanes 1 to 4: V9, V5, V19 and V12 XbaI PFGE profiles. Lanes 5 to 8: V9, V5, V19 and V12 S1 PFGE profiles. Panel B. Lanes 1 to 4: V6, V11, V16 and V18 XbaI PFGE profiles. Lanes 5, 7, 9 and 11: V6, V11, V16 and V18 S1 PFGE profiles. Lanes 6, 8, 10 and 12: transconjugants of V6, $\mathrm{V} 11, \mathrm{~V} 16$ and V18 S1 profiles. The asterisks indicate a negative result for class 1 integron hybridisation. Panel C. Lane 1: V1 XbaI PFGE profile. Lane 2: transconjugant of V1 S1 profile. No plasmid was observed on the donor strain 
$[10,11]$. The genetic environment of this $\beta$-lactamase consists of a complex integron called In60 which is playing an active role in the dissemination of $b l a_{\text {CTX-M-9 }}$ in different Enterobacteriaceae, including S. enterica. This genetic element was first described in E. coli, which has largely been studied since García et al. [12]. The typical structure of In60 was detected in all isolates except V16, the only strain negative for the amplification of a class 1 integron. This result is supported by our hybridisation results, where only the $b l a_{\mathrm{CTX} \text {-M-9 }}$ probe gave a positive result, suggesting a deletion of In60. The donor strains V1, V7 and V10 did not present any plasmids by $\mathrm{S} 1$ digestion, although hybridisation of the XbaI fragments with the $b l a_{\mathrm{CTX}-\mathrm{M}-9}$ and class 1 integron probes were positive. Plasmids of 330, 275 and $330 \mathrm{~kb}$, respectively, were observed after conjugation, and hybridisation of the $\mathrm{S} 1$ profiles using both probes was also positive. These results suggest a chromosomal location of the In60 integron and the mobilisation of this integron after conjugation.

All transconjugants were positive for HI2 replicon except that of V18, which was also positive for FIB, supporting the hypothesis of plasmid fusion. The characterisation of $S$. Virchow by phage typing, PFGE, resistance properties and analysis of plasmids highlight the emergence of a multiresistant CTX-M-9-producing S. Virchow PT19 clone in Spain. This seems to be linked to the spread of closely related plasmids that share the HI2 replication system and are in the same niche of the $\beta$-lactamase, In60, and differ in additional resistance genes. Although $S$. Virchow PT19 CTX-M-9-producer has been reported in previous studies $[10,11]$, this is the first time that the real cover of this multiresistant strain in Spain has been investigated. Moreover, our data suggest that these plasmids are related to those reported in E. coli, where similar plasticity, including plasmid fusion and the presence of In60 on the chromosome, have been described [12]. It is important to underline that these plasmids harbour multiple resistances to antibiotics widely used in animals and humans. Thus, the use of a single specific antimicrobial agent could maintain the collection of plasmids in nature, allowing the exchange of resistance genes within different bacterial species and between genera.

Acknowledgements The work carried out at the University of Oviedo has been supported by project FIS PI080656 of the Ministerio de Ciencia e Innovación, Spain. Irene Rodríguez is the recipient of a grant from the Fundación para el Fomento en Asturias de la Investigación Científica Aplicada y la Tecnología (FICYT-BP04-
086). We are grateful to Ana Aladueña for her assistance with the phage typing of the Salmonella isolates.

\section{References}

1. Bertrand S, Weill FX, Cloeckaert A, Vrints M, Mairiaux E, Praud K, Dierick K, Wildemauve C, Godard C, Butaye P, Imberechts H, Grimont PA, Collard JM (2006) Clonal emergence of extendedspectrum $\beta$-lactamase (CTX-M-2)-producing Salmonella enterica serovar Virchow isolates with reduced susceptibilities to ciprofloxacin among poultry and humans in Belgium and France (2000 to 2003). J Clin Microbiol 44:2897-2903

2. Mazel D (2006) Integrons: agents of bacterial evolution. Nat Rev Microbiol 4:608-620

3. Weinberger M, Solnik-Isaac H, Shachar D, Reisfeld A, Valinsky L, Andorn N, Agmon V, Yishai R, Bassal R, Fraser A, Yaron S, Cohen D (2006) Salmonella enterica serotype Virchow: epidemiology, resistance patterns and molecular characterisation of an invasive Salmonella serotype in Israel. Clin Microbiol Infect 12:999-1005

4. Chambers RM, McAdam P, de Sa JDH, Ward LR, Rowe B (1987) A phage-typing scheme for Salmonella Virchow. FEMS Microbiol Lett 40:155-157

5. National Committee for Clinical Laboratory Standards (NCCLS) (2007) Performance standards for antimicrobial susceptibility testing, document M100-S17. NCCLS, Wayne, PA

6. Rodríguez I, Rodicio MR, Herrera-León S, Echeita A, Mendoza MC (2008) Class 1 integrons in multidrug-resistant non-typhoidal Salmonella enterica isolated in Spain between 2002 and 2004. Int J Antimicrob Agents 32:158-164

7. Sabaté M, Navarro F, Miró E, Campoy S, Mirelis B, Barbé J, Prats G (2002) Novel complex sul1-type integron in Escherichia

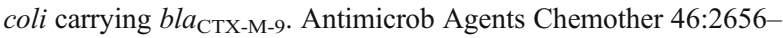
2661

8. Baucheron S, Imberechts H, Chaslus-Dancla E, Cloeckaert A (2002) The AcrB multidrug transporter plays a major role in high-level fluoroquinolone resistance in Salmonella enterica serovar typhimurium phage type DT204. Microb Drug Resist 8:281-289

9. Carattoli A, Bertini A, Villa L, Falbo V, Hopkins KL, Threlfall EJ (2005) Identification of plasmids by PCR-based replicon typing. J Microbiol Methods 63:219-228

10. Riaño I, García-Campello M, Sáenz Y, Alvarez P, Vinué L, Lantero M, Moreno MA, Zarazaga M, Torres C (2009) Occurrence of extended-spectrum $\beta$-lactamase-producing Salmonella enterica in northern Spain with evidence of CTX-M-9 clonal spread among animals and humans. Clin Microbiol Infect 15:292295

11. Weill FX, Lailler R, Praud K, Kérouanton A, Fabre L, Brisabois A, Grimont PA, Cloeckaert A (2004) Emergence of extended-spectrum$\beta$-lactamase (CTX-M-9)-producing multiresistant strains of Salmonella enterica serotype Virchow in poultry and humans in France. J Clin Microbiol 42:5767-5773

12. García A, Navarro F, Miró E, Villa L, Mirelis B, Coll P, Carattoli A (2007) Acquisition and diffusion of bla $a_{\text {CTX-M-9 }}$ gene by R478IncHI2 derivative plasmids. FEMS Microbiol Lett 271:71-77 